\title{
EVALUASI PERHITUNGAN KAPASITAS JALAN MAUL ANA YUSUF DENGAN MENGGUNAKAN METODE MANUAL KAPASITAS JALAN INDONESIA (MKJI)
}

\author{
Dine Agustine ${ }^{1}$, Abdul Basid ${ }^{2}$,Fathy Anisawitri ${ }^{3}$, Kevin Ago Irwan ${ }^{4}$, Muhammad Hawari Jafar ${ }^{5}$, Mita \\ Septiani Amalia ${ }^{6}$, Khalimatusaadiyah $^{7}$
}

Prodi Teknik Sipil, Fakultas Teknik, Universitas Islam Syekh Yusuf, Jl. Mulana Yusuf No.10 Tangerang Banten 15118, Indonesia

\author{
${ }^{1)}$ dine@unis.ac.id \\ ${ }^{2)}$ doelsid@yahoo.com
}

\begin{abstract}
Abstrak. Jalan memiliki perananan penting dalam melakukan kegiatan atau aktifitas sehari-hari dalam berkendara, karena dengan adanya jalan suatu daerah dapat terbantu dari segi perkembangan ekonomi, perkembangan sosial serta dapat menggunakan waktu secara efektif dan efisien. Namun berkembangnya suatu zaman membuat banyak permasalahan pada suatu jalan salah satunya jalan Maulana Yusuf. Jalan Maulana Yusuf yang terletak di kelurahan Babakan kecamatan Tangerang Kota Tangerang, persis didepan kampus Universitas Islam syekh Yusuf Tangerang. Jalan dengan panjang 375 meter ini yang menghubungnkan Jalan Perintis Kemerdekaan menuju Jalan Veteran ini terdiri dari dua jalur dengan sistem satu arah. Jalan kota dengan sistem jaringan sekunder yang menghubungkan antar pusat pelayanan kota dan masuk kategori jalan Kelas III C. Jalan dengan lebar 7,5 meter serta trotoar di masing-masing sisi 1 meter ini memiliki banyak masalah salah satunya kepadatan lalu lintas dari berbagai faktor, diantaranya banyaknya debit kendaraan terutama pada jam sibuk, posisi kampus yang mengahambat keluar masuk kendaraan, pedagang kaki lima, penyebrang jalan, serta parkir kendaraan. Dari permasalahan diatas penulis melakukan penelitian di jalan Maulana Yusuf. Penelitian ini dilakukan selama 10 (sepuluh) hari dengan jam-jam tertentu. Perbandingan volume kendaraan dimulai hari senin sampai minggu sangat terlihat padat pada hari kerja yaitu hari senin sampai hari jumat. Sedangkan hari sabtu dan minggu terlihat volume kendaraan berkurang, apalagi adanya kegiatan Car Free Day. Kecepatan rata - rata kendaraan ringan didapat yaitu 28,81 km/jam. Sedangkan untuk kendaraan sepeda motor didapat 32,39 $\mathrm{km} / \mathrm{jam}$ dengan kapasitas jalan 2321 SMP/jam.
\end{abstract}

Kata kunci : Kapasitas jalan, tingkat pelayanan, kinerja , jumlah pengguna jalan.

Abstract. [EVALUATION OF ROAD CAPACITY CALCULATION OF MAULANA YUSUF ROAD USING INDONESIAN ROAD CAPCITY MANUAL METHOD (MKJI]). Road has an important role in carrying out activities or daily activities in driving, because with the existence of a road an area can be helped in terms of economic development, social development and can use the time effectively and efficiently. But the development of an age caused many problems on one street Maulana Yusuf road. Maulana Yusuf Road located in Babakan village Tangerang sub-district Tangerang City, just in front of the campus of Islamic University sheikh Yusuf Tangerang. This 375-meter-long road that connects Independence Path to Veterans Street consists of two lines with one-way system. The city road with a secondary network system that connects between urban service centers and classified as Class III C. Roads with a width of 7.5 meters and sidewalks on each side of 1 meter has many 
problems one of which traffic density of various factors, including the number of vehicle discharge especially during rush hour, campus position that mengahambat out of the vehicle, street vendors, penyebrang road, and parking vehicles. From the above problems the authors do research on the road Maulana Yusuf. This research was conducted for 10 (ten) days with certain hours. Comparison of vehicle volume starts from Monday to Sunday is very visible solid on weekdays ie Monday to Friday. While on Saturdays and Sundays there is reduced vehicle volume, let alone Car Free Day activities. Average speed of light vehicles obtained is $28.81 \mathrm{~km} / \mathrm{hour}$. As for the motorcycle vehicle obtained $32.39 \mathrm{~km} / \mathrm{h}$ with road capacity of 2321 SMP / hour.

Keywords: Road capacity, service level, performance, number of road users.

\section{PENDAHULUAN}

\section{a. Latar Belakang Masalah}

Perkembangan jalan raya merupakan salah satu hal yang selalu beriringan dengan kemajuan teknologi dan pemikiran manusia yang menggunakannya, sehingga dalam hal ini jalan merupakan bagian yang cukup penting dan selalu di tuntut agar bisa menunjang perkembang suatu Daerah / Kota guna memperlancar akses kegiatan, baik di dalam daerah itu sendiri maupun den gan daerah lain. dari sekian banyak daerah yang berkembang di Indonesia, Kota Tangerang merupakan salah satu daerah yang selalu berusaha meningkatkan pelayanan dan prasarana transportasi bagi kepentingan masyarakatnya.

Lalu lintas merupakan salah satu sarana komunikasi masyarakat yang memegang peranan vital dalam memperlancar pembangunan yang kita laksanakan, karena dengan adanya lalu lintas tersebut,memudahkan akses bagi masyarakat untuk melakukan kegiatannya untuk pemenuhan perekonomiannya. Tanpa adanya lalu lintas,dapat dibayangkan bagaimana sulitnya kita untuk menuju tempat pekerjaan atau melakukan pekerjaan yang berhubungan dengan penggunaan jalan raya. (Daryanto, Arie : 2012).

Tidak ada satu pun pekerjaan yang tidak luput dari penggunaan lalu lintas (Kurnawan, 2013)>

Pentingnya transportasi tersebut tercermin pada semakin meningkatnya kebutuhan akan jasa angkutan bagi mobiltas orang serta barang dari dan ke seluruh pelosok tanah air,bahkan dari dalam dan luar negeri. Disamping itu transportasi juga berperan sebagai penunjang, pendorong, dan penggerak bagi pertumbuhan daerah yang berpotensi, namun belum berkembang, dalam upaya peningkatan dan pemerataan pembangunan serta hasil-hasilnya. ${ }^{1}$

\footnotetext{
${ }^{1}$ 1C.S.T. Kansil, dkk, Disiplin Berlalu Lintas di Jalan Raya, P.T. Rineka cipta, Jakarta 1995, hlm. 4
}

Dibalik manfaat lalu lintas tersebut, terdapat juga berbagai permasalahan yang berkaitan dengan penggunaan jalan raya. Seperti banyaknya pengguna jalan raya setiap hari, tidak mungkin luput dari permasalahan lalu lintas. Salah satunya Jalan Maulana Yusuf di Kota Tangerang.

Jalan Maulana Yusuf berada di kelurahan Babakan kota Tangerang yang persis didepan kampus Universitas Islam Syekh Yusuf. Jalan yang panjangnya 375 meter ini menghubungkan Jalan Perintis Kemerdekaan menuju Jalan Veteran. Jalan yang terdiri dari dua jalur dan menggunakan sistem satu arah ini tak luput dari permasalahan seperti kemacetan akibat kepadatan aktivitas. Seperti banyaknya kendaraan keluar dan masuk Kampus Universitas Islam syekh yusuf, pedagang kaki lima yang berada di trotoar, parkir kendaraan yang tidak tertata, angkutan umum yang menaik turunkan penumpang tidak pada halte, banyak nya jumlah kendaraan yang melewati Jalan Maulana Yusuf terutama pada saat jam - jam sibuk. Sehingga menyebabkan kemacetan di jalanan tersebut.

Kemacetan adalah kondisi dimana terjadi penumpukan kendaraan di jalan. Penumpukan tersebut disebabkan karena banyaknya kendaraan tidak mampu diimbangi oleh sarana dan prasana lalu lintas yang memadai. Akibatnya, arus kendaraan menjadi tersendat dan kecepatan berkendara pun menurun. Rata-rata kecepatan berkendara di Kota Tangerang saat ini berada di kisaran $15 \mathrm{~km} / \mathrm{jam}$, yang menurut standar internasional angka ini tergolong sebagai macet. Angka ini di bawah angka kecepatan berkendara di kota di dunia, seperti misalnya Tokyo. Data ini menunjukkan bahwa kondisi kemacetan di Kota Tangerang cukup parah. Kemacetan ini disebabkan karena melonjaknya jumlah kendaraan bermotor yang ada di Kota Tangerang. Tingginya tingkat pertumbuhan kendaraan bermotor di Kota Tangerang ini tidak diimbangi oleh meningkatnya 


\section{Jurnal Keilmuan dan Aplikasi Teknik \\ UNISTEK, 2018, Edisi 5, No.2}

sarana dan prasarana lalu lintas yang memadai. Pertumbuhan jumlah kendaraan bermotor di Kota Tangerang diperkirakan berada di kisaran 5-10\% per tahun dengan motor sebagai porsi terbesar penyumbangnya. Berbanding kontras dengan pertumbuhan jumlah kendaraan bermotor, pertumbuhan panjang jalan bahkan kurang dari $1 \%$ per tahunnya. Akibatnya, kendaraan bermotor semakin menumpuk di jalanan Tangerang dan kemacetan pun tidak terhindari.

Kemacetan pada akhirnya menimbulkan banyak sekali kerugian terhadap masyarakat dan negara. Kerugian yang paling nyata adalah pemborosan bahan bakar. Padahal pemborosan ini membuat uang seharusnya digunakan/dialokasikan masyarakat untuk penggunaan lain harus dikeluarkan untuk biaya transportasi. Kondisi ini jelas merugikan masyarakat. Selain itu, kemacetan juga menciptakan dampak yang lainnya, yaitu kerusakan lingkungan akibat polusi udara yang dikeluarkan oleh kendaraan bermotor.

Berdasarkan permasalahan yang sering terjadi di Jalan Maulana Yusuf Tangerang, maka penulis ingin meneliti “Analisis Jalan Maulana Yusuf Ditinjau dari Segi Lalu Lintas Dan Jumlah Pengguna Jalan" untuk menyelesaikan permasalahan yang ada.

\subsection{Identifikasi Masalah}

Dalam hal ini penulis akan menjelaskan identifikasi masalah pada ruas Jalan Maulana Yusuf Tangerang. Adapun identikasi masalah tersebut diantaranya :

1. Luas penampang jalan Maulana Yusuf dengan lebar badan jalan 7,5 meter terdiri dari dua lajur dan menggunakan sistem satu arah ini diperuntukan untuk dilewati kendaraan kecil namun realitasnya kendaraan besar sering melewati jalan tersebut.

2. Dengan semakin bertambahnya jumlah kendaraan bermotor di Kota Tangerang, terutama pada ruas Jalan Maulana Yusuf, mengakibatkan aktivitas lalu lintas meningkat. Mengingat daerah ruas jalan tersebut dilihat dari karakteristik kepadatan arus lalu lintasnya adalah sangat padat apalagi pada jam-jam tertentu

3. Belum adanya Perda dan rambu yang mengatur tentang parkir kendaraan dan pedagang di sepanjang Jalan Maulana Yusuf.
4. Posisi pintu keluar dan masuk kendaraan di Universitas Islam Syekh Yusuf yang kurang proposional, sehingga mengakibatkan perlambatan arus lalu lintas.

5. Kurangnya kesadaran pengguna jalan yang melawan arus.

6. Belum adanya traffic light maupun Zebra Cross bagi pejalan kaki, sehingga masih ditemukannya pejalan kaki yang menyebrang sembarangan.

7. Angkutan Umum yang menaik turunkan penumpang sembarangan, sehingga menghambat arus lalu lintas.

\subsection{Batasan Masalah}

Agar lebih jelas dan berfokus, maka ruang lingkup penelitian di batasi dan lingkup penelitiannya mencakup sebagai berikut :

1. Penelitian dilakukan pada ruas Jalan Maulana Yusuf sepanjang 375 meter. Dimulai dari Perempatan lampu merah Jalan Perintis kemerdekaan sampai persimpangan Jalan Veteran

2. Tingkat kepadatan kendaraan yang diteliti hanya dilakukan 7 hari dan pada jam-jam tertentu.

3. Menganalisis kapasitas kendaraan pada Jalan Maulana Yusuf Tangerang

4. Analisis penyebab kepadatan pada ruas Jalan Maulana Yusuf Tangerang.

5. Menganalisis pengawasan peraturan daerah tentang Jalan Maulana Yusuf.

\subsection{Rumusan Masalah}

Dari latar belakang masalah diatas dapat diajukan rumusan masalah: "Menganalisis volume arus lalu lintas dan kapasitas Jalan Maulana Yusuf. Sehingga akan didapatkan kesimpulan. Apakah kapasitas Jalan Maulana Yusuf masih memenuhi standar sesuai Metode Manual Kapasitas Jalan Indonesia (MKJI)"

\subsection{Kegunaan dan Hasil Penelitian}

\section{Secara Teoritis}




\section{Jurnal Keilmuan dan Aplikasi Teknik}

UNISTEK, 2018, Edisi 5, No.2

Menambah pengetahuan wawasan dan pemahaman dalam penulisan karya ilmiah, dimana merupakan sarana untuk memaparkan dan memantapkan ilmu pengetahuan yang telah diperoleh dalam masa perkuliahan

\section{Secara Praktis}

a. Guna memenuhi salah satu pesyaratan untuk memperoleh gelar Sarjana Teknik pada Program Studi Teknik Sipil Universitas Islam Syekh Yusuf Tangerang.

b. Untuk memberikan sumbangan pemikiran bagi para pembaca dan agar masyarakat mengetahui tentang kesadaran lalu lintas dan mengoptimalkan fungsi jalan raya tersebut.

\section{KAJIAN TEORITIK}

\subsection{Pengertian Analisis}

Pengertian Analisis berarti melakukan evaluasi terhadap kondisi dari pos-pos atau ayat-ayat yang berkaitan dengan akuntansi dan alasan-alasan yang memungkinkan tentang perbedaan yang muncul. ${ }^{2}$

Analisis adalah aktivitas yang memuat sejumlah kegiatan seperti mengurai, membedakan, memilah sesuatu untuk digolongkan dan dikelompokkan kembali menurut kriteria tertentu kemudian dicari kaitannya dan ditaksir maknanya. (Wiradi, 1998).

\subsection{Pengertian Kapasitas}

Kapasitas adalah tingkat kemampuan berproduksi secara optimum dari sebuah fasilitas biasanya dinyatakan sebagai jumlah output pada satu periode waktu tertentu. Manajer Operasional

\footnotetext{
${ }^{2}$ Prof. Dr. H.R. Riyadi Soeprapto MS, The Capacity Building For Local Government Toward Good Governance, (Jakarta: 2010) .
}

memperhatikan kapasitas karena pertama, mereka ingin mencukupi kapasitas untuk memenuhi permintaan konsumen. Kedua, kapasitas mempengaruhi efisiensi biaya operasi. Ketiga, kapasitas sangat bermanfaat mengetahui perencanaan output, biaya pemeliharaan kapasitas, dan sangat menentukan dalam analisis kebutuhan investasi. ${ }^{3}$

\subsection{Pengertian Jalan}

Jalan adalah prasarana transportasi darat yang meliputi segala bagian jalan, termasuk bangunan pelengkap dan perlengkapannya yang diperuntukkan bagi lalu lintas, yang berada pada permukaan tanah, di atas permukaan tanah, di bawah permukaan tanah dan/atau air, serta di atas permukaan air, kecuali jalan kereta api, jalan lori, dan jalan kabel. $^{4}$

Dapat disimpulkan jalan merupakan jalan utama yang menghubungkan satu kawasan dengan kawasan yang lain.

\subsection{Pengertian Lalu Lintas}

Menurut poerwadarminta dalam kamus umum bahasa Indonesia (1993:55) menyatakan bahwa lalu lintas adalah berjalan bolak balik, hilir mudik dan perihal perjalanan di jalan dan sebagainya serta berhubungan antara sebuah tempat dengan tempat lainnya.

Di dalam Undang-undang No 22 tahun $2009^{5}$ didefinisikan sebagai gerak Kendaraan dan orang di Ruang Lalu Lintas Jalan, sedang yang dimaksud dengan Ruang Lalu Lintas Jalan adalah prasarana yang diperuntukkan bagi gerak pindah

\footnotetext{
${ }^{3}$ Raharjo Adi Sasmita dan Sakti Adji Adisasmita, MANAJEMEN TRANSPORTASI DARAT, Yogyakarta: Graha Ilmu, 2011, hlm. 12.

${ }^{4}$ http://id.wikipedia.org/wiki/Transportasi

${ }^{5}$ Undang-undang No 22 tahun 2009 tentang Lalu Lintas dan Angkutan Jalan
} 
Kendaraan, orang, dan/atau barang yang berupa Jalan dan fasilitas pendukung.

\subsection{Pengertian Pengguna Jalan}

Pengguna Jalan adalah orang yang menggunakan Jalan untuk berlalu lintas. ${ }^{6}$

Dapat disimpulkan pengguna jalan merupakan orang yang menggunakan system jalan dan yang mengendalikan pergerakan kendaraan atau dirinya sendiri. Berdasarkan definisi tersebut, dikelompokkan dua pengguna jalan yaitu pengemudi dan pejalan kaki. ${ }^{7}$

\section{METODOLOGI PENELITIAN}

\subsection{Tujuan Penelitian}

1. Untuk menganilisis penyebab kemacetan di Jalan Maulana Yusuf.

2. Untuk menganalisis dampak yang ditimbulkan dari peristiwa kemacetan setiap harinya di Jalan Maulana Yusuf.

3. Untuk menganalisis cara mengurangi kemacetan yang setiap harinya terjadi di Jalan Maulana Yusuf.

4. Untuk menganalisis kapasitas Jalan Maulana Yusuf.

\subsection{Tempat dan Waktu Penelitian}

\section{A.Tempat Penelitian}

Penelitian dilakukan di Jalan Maulana Yusuf berada di kelurahan Babakan Kecamatan Tangerang kota Tangerang yang lokasinya persis didepan kampus Universitas Islam Syekh Yusuf Tangerang.

\section{B. Waktu Penelitian}

\footnotetext{
${ }^{6}$ Pasal 1 Angka 27 UU Nomor 22 Tahun 2009

Tentang Lalu Lintas Dan Angkutan Jalan

${ }^{7}$ Andrew R. Cecil, et al, Penegakan Hukum Lalu Lintas, Bandung: Nuansa, 2011, hlm. 28.
}

Waktu penelitian dilaksanakan mulai dari tanggal 08 Mei 2017 sampai 14 Mei 2017 dan tanggal 23, 25 \& 27 Oktober 2017. Dalam rentang waktu :

a). Pagi Jam 07:00 WIB - 10:00 WIB

b). Siang Jam 12:30 WIB - 15:30 WIB

c). Sore Jam 17:00 WIB - 20:00 WIB

\subsection{Metode Penelitian}

Dalam Penelitian kuantitatif ini penulis menggunakan metode deskriptif studi kasus. Dimana penulis merumuskan masalah dan studi pustaka. Menentukan tempat penelitian dan mempersiapkan alat yang digunakan dalam penelitian.

Kemudian melakukan pengumpulan data berupa data primer dan data sekunder. Data Primer yang merupakan sumber data yang diperoleh langsung darinsumber asli ( tidak melalui media perantara), data tersebut diantaranya :

1. Geometrik Jalan

2. Jenis Hambatan Samping

3. Volume Lalu Lintas

4. Jenis Kendaraan

Data sekunder merupakan sumber data penelitian yang diperoleh melalui media perantara (diperoleh dan dicatat oleh pihak lain), data yang penulis dapatkan merupakan data yang didapat dari Dinas Pekerjaan Umum (PU) Kota Tangerang, Dinas Perhubungan (DisHub) Kota Tangerang, dan data social dari warga sekitar jalan Maulana Yusuf. Data yang dimaksud diantaranya :

a). Data sosial berupa data penduduk

b). Tingkat pelayanan yang meliputi marka jalan, perda, rambu lalu lintas yang di dapat dari Dinas Perhubungan Kota Tangerang. 
c). Kinerja jalan yang di dapat dari Dinas Pekerjaan Umum Kota Tangerang.

Setelah proses penggabungan data, dilakukan analisa kapasitas Jalan Maulana Yusuf untuk mengetahui kapasitas terhadap jalan tersebut. Kemudian membuat menyimpulkan hasil penelitian.

\subsection{Teknik Pengumpulan Data}

Teknik pengumpulan data yang digunakan penulis yaitu dengan melakukan survey atau menganilisis langsung jalan Maulana Yusuf pada tanggal dan jam yang telah ditentukan.

\subsection{Teknik Analisa Data}

Teknik analisa data yang dilakukan penulis yaitu dengan menggunakan Analisis Matematis, yaitu melakukan perhitungan dengan rumus-rumus matematis. Yang bertujuan untuk mengetahui kapasitas jalan Maulana Yusuf Ditinjau Dari Segi Lalu Lintas Dan Jumlah Pengguna Jalan.

\section{HASIL PENELITIAN DAN PEMBAHASAN}

\subsection{Data Geometrik}

Disadari bersama, bahwa jalan sebagai salah satu prasarana transportasi merupakan unsur penting dalam pengembangan kehidupan berbangsa dan bernegara serta dalam memajukan kesejahteraan umum sebagaimana tercantum dalam Undang undang Nomor 38 Tahun 2004 tetntang jalan. Dalam menganalisis ruas jalan diperlukan berbagai data yang diperoleh dari hasil survey. Data-data ini kemudian diolah sesuai dengan hasil yang ingin dicapai. Jalan Maulana Yusuf yang berada di kelurahan Babakan kecamatan Tangerang. Tepat di depan Universitas Islam Syekh Yusuf Tangerang. Jalan yang panjangnya 375 meter yang menghubungkan Jalan Perintis Kemerdekaan menuju Jalan Veteran dan menggunakan sistem satu arah. Jalan yang lebarnya 7,5 meter dengan dua lajur dimana masing-masing lajur memiliki lebar yang sama yaitu 3,75 meter. Keterangan mengenai data geometrik jalan dapat dilihat pada Tabel.

Tabel 14

Data Geometrik Jalan

\begin{tabular}{|c|c|c|c|c|c|c|}
\hline Tip & Panj & Salur & Trot & Ba & Bad & Med \\
e & ang & an & oar & hu & an & ian \\
Jal & Jalan & Drain & & Jal & Jala & Jala \\
an & & ase & & an & n & n \\
\hline 2 & 375 & 1,00 & 1,50 & 000 & 7,50 & 000 \\
laju & meter & meter & meter & & met & \\
r & & & & & er & \\
sat & & & & & & \\
u & & & & & & \\
ara & & & & & & \\
h & & & & & & \\
(2/ & & & & & & \\
1) & & & & & & \\
\hline
\end{tabular}

\subsection{Data Volume Lalu Lintas}

Survey volume lalu lintas dilakukan pada tanggal 08 Mei 2017 sampai 14 Mei 2017 pada ruas Jalan Maulana Yusuf. Data kemudian dikelompokkan dengan rentang waktu:

a. Pagi Jam 07:00 WIB - 09:00 WIB

b. Siang Jam 12:30 WIB - 15:30 WIB

c. Sore Jam 17:00 WIB - 20:00 WIB

Data volume lalu lintas hasil survey selengkapnya dapat dilihat pada tabel, dimana terdapat data volume kendaraan yang melewati jalan Maulana Yusuf.

\subsection{Data Hambatan Samping}

Dalam menghitung frekuensi kejadian hambatan samping terlebih dahulu jenis kendaraan harus dikalikan dengan faktor bobot. Penentuan kelas hambatan samping untuk mendapatkan faktor 
hambatan samping FFVsf dan Fcsf berdasarkan tabel

bobot kejadian.

Adapun hasil survey untuk data hambatan samping di Jalan Maulana Yusuf selama 7 (tujuh) hari tertuang dalam tabel ( lampiran). Sementara untuk data yang akan dihitung adalah data hasil survey dihari tersibuk yaitu pada hari senin, kamis dan minggu.

Survey hambatan samping dilakukan sepanjang jalan Maulana Yusuf . Tipe kejadian digolongkan antara lain, jumlah pejalan kaki berjalan atau menyebrang sepanjang segmen jalan (PED/pedestarian), jumlah kendaraan berhenti atau parkir (PSV/Parking and Slow Vehicle), jumlah kendaraan bermotor yang masuk dan keluar dari samping jalan atau yang melawan arus lalu lintas (EEV/Entry and Exit Vehicles). Data hasil pengamatan hambatan samping dapat dilihat ada tabel sebagai berikut :

Tabel 22

Frekuensi bobot kejadian hambatan samping berdasarkan tipe hambatan samping

\begin{tabular}{|c|c|c|c|}
\hline Hari & PED & PSV & EEV \\
\hline Senin & 603 & 124 & 1801 \\
\hline Kamis & 555 & 371 & 2562 \\
\hline Minggu & 1293 & 262 & 279 \\
\hline Jumlah & $\mathbf{2 4 5 1}$ & $\mathbf{7 5 7}$ & $\mathbf{4 6 4 2}$ \\
\hline Total & \multicolumn{3}{|c}{$\mathbf{7 8 5 0}$} \\
\hline
\end{tabular}

Sumber Hasil Penelitian

\section{4 . Data Kapasitas Jalan}

Perhitungan kapasitas jalan dihitung dengan persamaan sebagai berikut :

$\mathrm{C}=\mathrm{Co} \times \mathrm{FCw} \times \mathrm{FCsp} \times \mathrm{FCsf} \times$

FCcs

$$
\begin{aligned}
& =2900 \times 0,87 \times 1,00 \times 0,92 \times 1,00 \\
& =2321 \mathrm{SMP} / \mathrm{jam} .
\end{aligned}
$$

\subsection{Analisis Volume Jam Puncak}

Dalam menganalisis volume jam puncak yang harus diketahui adalah volume kendaraan terklasifikasi menjadi volume sepeda motor, volume kendaraan ringan, dan volume kendaraan berat yang melintasi segmen jalan tempat pelaksanaan survey dalam rentang waktu tertentu. Setelah data diperoleh, kemudian dikalibrasi menggunakan nilai EMP yang telah ditentukan.

Fluktuasi volume sepeda motor yang melintasi ruas jalan Maulana Yusuf dapat terlihat dengan jelas pada gambar .. perubahan drastis volume lalu lintas terjadi pada jam - jam pagi yaitu mulai pukul 07:00 WIB sampai pukul 10:00 WIB. Jumlah sepeda motor pada pagi hari sangat sedikit sedangkan hanya 30 menit kemudian, jumlah sepeda motor yang melintas bertambah dengan sangat banyak bahkan mencapai jam puncaknya pada selang waktu tersebut. Hal ini kemungkinan diakibatkan oleh arus kendaraan yang menggunakan untuk mengantar siswa ke sekolah dan pergerakan orang orang dengan tempat aktifitas yang cukup jauh sehingga memerlukan waktu yang lebih lama untuk melakukan perjalanan. Perhitungan volume jam puncak dapat dilihat pada lampiran. Berikut adalah hasil penelitian volume lalu lintas yang diambil pada hari senin dan minggu. 


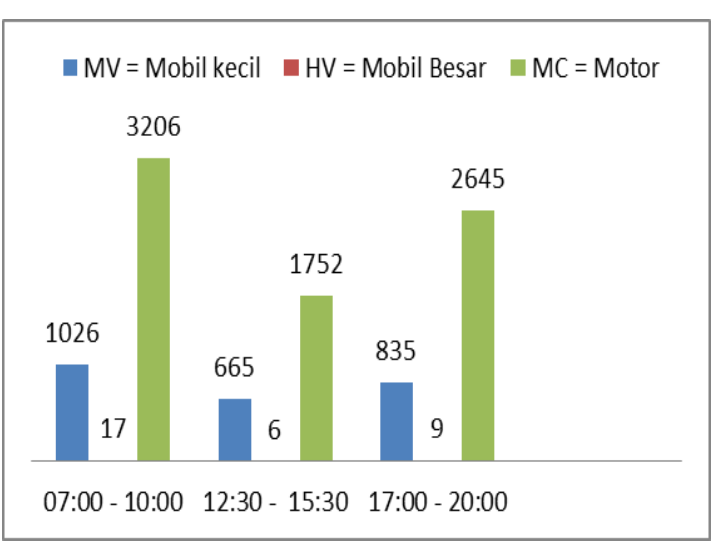

Gambar 1

Volume Lalu lintas Pada Hari Senin

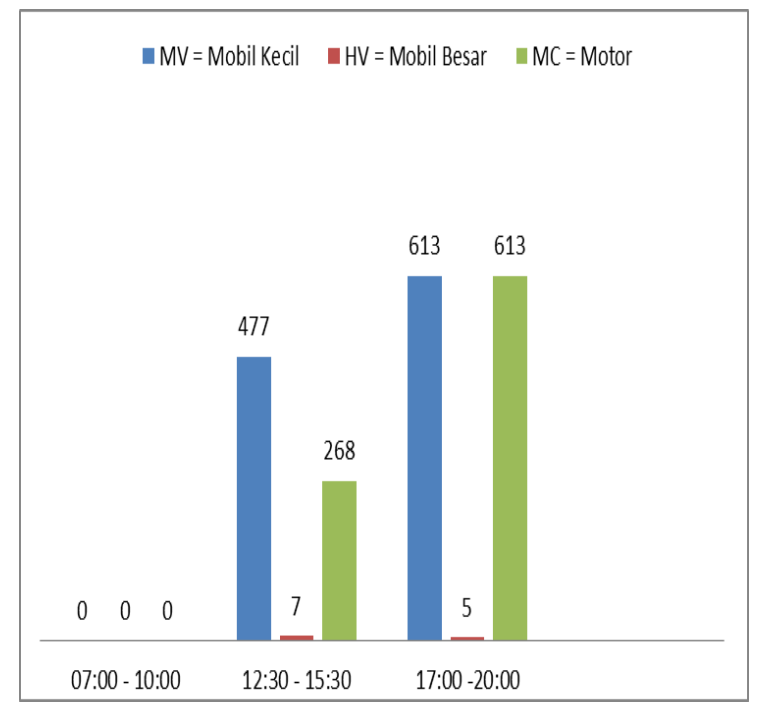

Gambar 2

Volume Lalu Lintas Pada Hari Minggu

Khusus pada hari Minggu tedapat kegiatan Car Free Day mulai pukul 07:00 sampai pukul 10:00 sehingga tidak adanya kendaraan yang melewati jalan tersebut.

\subsection{Analisis Kecepatan Rata - Rata}

Data yang dikumpulkan dari pengamatan lalu lintas, dianalisis untuk mendapatkan kecepatan rata - rata kendaraan. Hasil kecepatan rata - rata dalam survey waktu penelitian dalam rentang waktu per 1 jam yaitu :

a. Pagi Jam 07:00 WIB - 08:00 WIB

Hasil data terdapat pada tabel (Lampiran), jenis kendaraan yang dihitung di klasifikasikan sebagai berikut :

Kendaraan Ringan meliputi : mobil pribadi, angkutan umum

Kendaraan Berat

Sepeda Motor.

Kecepatan kendaraan yang diukur hanya kendaraan yang masuk dari Jalan Perintis Kemerdekaan sampai persimpangan Jalan Veteran.

Berikut merupakan hasil penelitian kecepatan rata -rata pada ruas Jalan Maulana Yusuf :

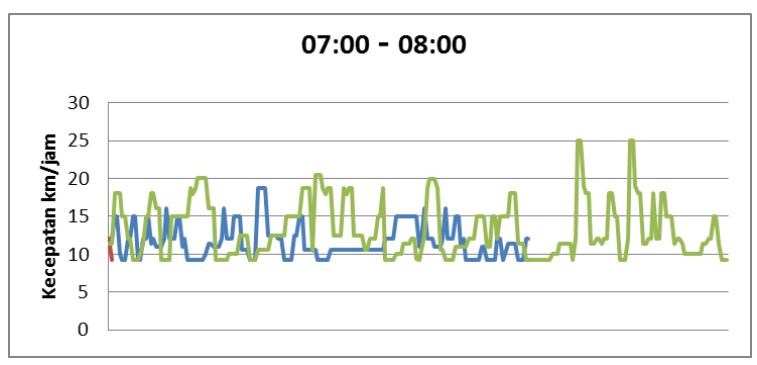

Gambar 3

Data Kecepatan Kendaraan Pukul 07:00 - 08:00 Pada gambar diatas dapat disimpulkan banyaknya kendaraan yang melewati jalan tersebut mengingat waktu penelitian pada pukul 07:00 sampai 08:00. Untuk kecepatan rata - rata kendaraan ringan didapat $11.69 \mathrm{~km} / \mathrm{jam}$, sedangkan untuk sepeda motor didapat kecepatan rata - rata yaitu $13,34 \mathrm{~km} / \mathrm{jam}$.

\subsection{Analisis Kinerja Ruas Jalan}




\section{Jurnal Keilmuan dan Aplikasi Teknik}

UNISTEK, 2018, Edisi 5, No.2

Analisis kinerja ruas jalan merupakan suatu langkah untu menentukan fungsi pelayanan suatu ruas/segmen jalan pada suatu kondisi tertentu. Analisis dilakukan terhadap kinerja jalan meliputi kecepatan arus bebas, kapasitas, derajat kejenuhan.

Secara umum, dapat dijelaskan bahwa jalan Maulana Yususf merupakan akses utama yang menghubungkan anatara jalan Perintis Kemerdekaan dengan jalan Veteran. Jalan tersebut memiliki tipe 2/1 UD berada dikawasan pendidikan yaitu kampus dan komersial yang didominasi oleh aktifitas perdagangan pada tiap sisi jalan dengan hambatan samping tinggi. Volume jam puncak tertinggi yang membebani jalan ini terjadi pada jam puncak pagi pukul 07:00 WIB sampai pukul 10:00 WIB dan juga pada hari kerja. Kapasitas dasar tipe untuk jalan ini sebesar $2321 \mathrm{SMP} / \mathrm{jam}$ per lajur.

Berdasarkan hasil analisis dapat diketahui, bahwa kinerja jalan Maulana Yusuf pada saat ini masih cukup baik dalam melayani volume lalu lintas yang ada, namun sudah harus diperhitungkan alternatif lain untuk membantu meringankan beban pada ruas ini. Hal ini ditandai dengan arus lalu lintas yang diperoleh dari hasil survei yang cukup besar yaitu 2321 SMP/jam. Dimana arus kendaraan mendekati tidak stabil dengan volume lalu lintas yang tinggi dan kecepatan yang masih bias ditolerir namun sangat terpengaruh oleh perubahan arus lalu lintas.

\section{KESIMPULAN DAN SARAN}

\subsection{Kesimpulan}

Dari hasil analisis yang peneliti lakukan pada jalan Maulana Yusuf Tangerang, dapat di ambil kesimpulan sebagai berikut :

1. Jalan Maulana Yusuf yang berada di kelurahan Babakan kecamatan Tangerang. Tepat di depan Universitas Islam Syekh Yusuf Tangerang. Jalan yang panjangnya 337 meter yang menghubungkan Jalan Perintis Kemerdekaan menuju Jalan Veteran dan menggunakan sistem satu arah. Jalan yang lebarnya 7,5 meter dengan dua lajur dimana masing-masing lajur memiliki lebar yang sama yaitu 3,75 meter.

2. Dari penelitian yang dilakukan, volume puncak terjadi pada jam-jam sibuk yaitu di pagi hari pukul 07:00 WIB sampai pukul 09:00 WIB

3. Perbandingan volume kendaraan dimulai hari senin sampai minggu sangat terlihat padat pada hari kerja yaitu hari senin sampai hari jumat. Sedangkan hari sabtu dan minggu terlihat volume kendaraan berkurang, apalagi adanya kegiatan Car Free Day

4. Karena total frekuensi hambatan samping bobot diatas 100, maka hambatan samping pada area survey termasuk kategori sangat tinggi.

5. Kecepatan rata - rata kendaraan ringan didapat yaitu $28,81 \mathrm{~km} / \mathrm{jam}$. Sedangkan untuk kendaraan sepeda motor didapat $32,39 \mathrm{~km} / \mathrm{jam}$.

6. Kinerja jalan Maulana Yusuf pada saat ini masih cukup baik dalam melayani volume lalu lintas yang ada, namun sudah harus diperhitungkan alternatif lain untuk membantu meringankan beban pada ruas ini.

\subsection{Saran}

Dari hasil pengamatan dan analisis yang peneliti lakukan, saran yang dapat saya berikan terhadap jalan Maulana Yusuf Tangerang adalah sebagai berikut :

1. Mengingat jalan Maulana Yusuf berada pada kawasan perkuliahan maka aktifitas sangat padat dan dibutuhkannya Zebra Cross atau Traffic Light untuk penyebrang jalan.

2. Perlu adanya halte untuk menaik turunkan penumpang oleh kendaraan umum.

3. Pemasangan rambu lalu lintas seperti dilarang parkir, berjualan pada trotoar serta dilarang untuk melawan arus.

4. Diubahnya posisi pintu keluar masuk kendaraan pada gerbang Universitas Islam Syekh Yusuf. 
5. Kesadaran bagi pengguna jalan agar selalu mentaati peraturan lalu lintas serta menghargai sesama pengguna jalan.

\section{DAFTAR PUSTAKA}

Andrew R. Cecil. et al. Penegakan Hukum Lalu Lintas. Bandung. Nuansa, 2011.

C.S.T. Kansil, dkk. Disiplin Berlalu Lintas di Jalan Raya. P.T. Rineka cipta. Jakarta, 1995.

Departemen Pemukiman dan Prasarana Wiayah. PdT-14 2003.Perencanaan Perkerasan Jalan Beton Semen. Departemen Pemukiman dan Prasarana Wiayah.

Direktorat Jendral Bina marga. Manuak Kapasitas Jalan Indonesia. 1997.

. H.R. Riyadi Soeprapto MS. The Capacity Building For Local Government Toward Good Governance . Jakarta: 2010.

http://id.wikipedia.org/wiki/Transportasi (diakse 23 Maret 2017, jam 14:55)

https://id.wikipedia.org/wiki/Jalan (diakse 23 Maret 2017, jam 15:31)

Raharjo Adi Sasmita. Sakti Adji Adisasmita. MANAJEMEN TRANSPORTASI DARAT. Yogyakarta: Graha Ilmu, 2011.

Undang-Undang Republik Indonesia .No 22 Tahun 2009 . Tentang Lalu Lintas dan Angkutan Jalan. Kep Dirjen Bina Marga. No.76/KPT/Db/1999. Tanggal 2O Desember 1999. 